\title{
Minimization of Casting Defects
}

\author{
Achamyeleh A. Kassie ${ }^{1}$, Samuel B. Assfaw ${ }^{2}$ \\ ${ }^{1,2}$ School of Mechanical and Industrial Engineering Bahirdar University, Bahirdar, Ethiopia,
}

\begin{abstract}
In this paper the statistical analysis is aimed to optimize process parameters at the case study, i.e. Akaki Basic Metals Industry (ABMI) in Addis Ababa Ethiopia, to minimize major steel casting defects. This project is intended to observe just two of the steel casting defects which are severe in their nature i.e., gas defects and shrinkage defects. In order to minimize these defects, four process parameters were studied like Sand - binder ratio, Mold permeability, Pouring Temperature and De-oxidant amount in three levels. In order to obtain a representative experimental data it was used a factorial experiment.. The relative influence of each factor on the casting defect/porosity/ was determined and suggestions have been given using the Statistical Analysis method by optimizing the process parameters.
\end{abstract}

Keywords: Steel Casting, Shrinkage defects, gas defects, mold and melting furnace

\section{INTRODUCTION}

Casting, one of the oldest manufacturing processes, dates back to 3000B.C. when copper arrowheads were made. Metal casting process considered to be the sixth largest industry in the USA. Casting process basically involve the introduction of a molten metal into a mold cavity, where upon solidification, the metal takes on the shape of the mold cavity. This industry is the major government owned model industry used not only for manufacturing metallic products but also used as a training and research center for all higher education engineering students and other researchers. The main concerns motivating the need for establishing this company was difficulty to find spare parts for old machineries from former suppliers, very long delivery time that required gross orders and huge capital, need to place special orders due to difficulty to obtain regular spare parts, high foreign currency requirement to import the required spare parts.

Akaki Basic Metals industry established to make metal melting, forging, machining, heat treatment, automotive maintenance and quality control. It was intended to respond to the need of spare parts for textile, sugar, cement industries, other construction supplies, metal industries, transport sector and to some extent to agriculture, energy and mines sector. The company can cast up to 4,500 tons of metal in two shifts annually. The ferrous foundry can melt nodular iron, grey iron, low carbon and alloyed steels. Among a large number of casting methods, ABMI utilizes the no-bake sand casting method for its advantages. There are a number of casting defects grouped under different classes. Very few casting defects may have no effect on the functionality or service life of casting products as long as they are within the engineering design specifications and could be easily corrected by any subsequent cleaning or grinding works. The ferrous foundry section in ABMI is experiencing the general imperfections due to voids in most of its steel (46MnSi4) castings. To some extent, the severity of these defects may result in a complete rejection of the part there by losing a huge amount of resources spent from product and casting design to final production. The company uses $46 \mathrm{MnSi} 4$ steel for a varieties of applications such as brake shoe plates, eccentric sleeves, stud head shafts, ring sprocket mount, trash plates, scraper plates, drive disks, concave spacer bearing housings, motor end shields, right and left hook holders, rollers, different pulleys and gears for a number of its customers that include Metehra Sugar Factory, Muger Cement Enterprise, Hibret Machine Shop, Abijata Soda Enterprise, Gafat Armament, Ziquala Steel Mill etc. The following methods are being used for inspecting the casting defects. Process inspection, Visual inspection, Chemical composition inspection, Pressure testing, Radiography, Magnetic particle or magna flux testing, Penetrate testing, Ultrasonic testing

\section{LITERATURE REVIEW}

Under practical circumstances castings, like all metallurgical products, contain voids, inclusions and other imperfections which contribute to normal quality impairment. Such imperfections begin to be regarded as true defects only when the satisfactory function or appearance of the product is in question. In such cases, the possibility of salvage, if worse, rejection and replacement should be considered. The decision should be based upon not only the defect itself but also upon the significance in relation to the service function of the casting and the quality and inspection standards being applied.

A defect may arise from a single clearly defined cause which enables the remedy to be more specific and straightforward. It may, however, result from a combination of factors, so that the necessary preventive measures are more obscure. All foundry men are familiar with the persistent defect which defies explanation and 
finally disappears without clarification of its original cause. Close control and standardization of all aspects of production technique offers the best protection against such troubles. More specific precautions can be taken in those cases where there is a known susceptibility to a particular defect, whilst the radical approach of design modification may need to be considered in the extreme cases which do not respond to changes in foundry technique. Defects can, above all, be minimized by a clear understanding of their fundamental causes. [1]

Due to the wide range of possible factors, reasonable classification of casting porosity [2] defects set difficulties. Some scholars classify casting defects based upon their morphology. They prefer identifying defects by direct observation of the defective casting or from a precise description of the defect, involving only the criteria of shape, appearance, location and dimensions. This classification, they assume to be more logical than one based upon causes since it requires no prior assumptions to be made. Others are more comfortable with the classification based upon the causes or origins of the defects. As the researcher in this project believes knowing the cause of a defect is a means to arrive at a best solution to get rid of the defect, the system of classification according to the causes will be adopted throughout this paper

Therefore, according to this classification, such defects may be described as follows:

a. gas defects, and

b. Shrinkage defects due to volume contraction in the liquid state and during solidification.

Different scholars have made varieties of researches on possible causes of porosity formation in different families of steel. They have made lots of experiments on different mold making materials, mold-metal interface reactions, atmospheric interactions, pouring temperatures, melt handling functions and other surrounding conditions which probably constitute the sources for gas defects. Molten metal is highly reactive material which can make every reaction with nearly all of its surroundings. For instance, its reaction with binders used in mold making for no bake systems usually produces decomposed gases in different levels. Since those gases can be entrapped in a metal and result gas defects, researchers made their studies in some of commonly known binders. [3]Dr. R.L. Naro in his investigations has studied the effect of the phenolic urethane no-bake (PUN) resin system that consists of two resin components. They are phenolic resin (poly-benzylicether-phenolic resin) or Part I, and a polymeric di-isocyanate resin or Part II. He studied the effects of these binders in the mold-metal interface to the porosity defect and rated the extent of porosity results found as nil to severe. In his experiment he selected a test casting design having a stepped core susceptible to porosity defects due to core decomposition gases. The majority of molds used for the production of test castings were made with a zero nitrogen no-bake furan binder. The base core sand mix used for most of the experimental work consisted of the phenolic urethane no-bake binder (PUN) mixed with a high purity, washed and dried, round grained, silica (W/D) sand. Pouring temperature has a fundamental effect on porosity formation in iron and steel castings. The effects of binder ratios and binder levels on porosity defects discussed above are highly dependent on pouring temperature with which a mold is filled.[3] Dr. R.L Naro conducted an experiment on the effects of temperature taking in to account the unbalanced Part I to Part II binder ratio of 35:65 which had normally resulted moderate to severe porosity defects in earlier binder ratio and level experiments

Another scholar, S.Kuyucak[4] has studied the influences of using a pouring cup (a standard gating) and a pouring basin (an alternative gating) on formation of surface quality problems on steel casting due to entrained air. His experiment constitutes two steel wedge-block castings poured from a bottom pouring ladle the first one utilizing a pouring cup and the second, a pouring basin with a dam, with or without a submerged ladle nozzle extension (shroud) into the pouring basin. Prior experiments showed that $30-60 \%$ air entrainment by volume in a typical ladle bottom pouring operations. [5]The air entrainment and thus surface defects increase with poured metal head height. The second poured blocks with the alternative gating had a lower metal head in the ladle, but the ladle was raised to clear the pouring basin thereby, decreasing the difference in pour heights between the two castings. The average pour heights taken from average metal head in the ladle to sprue base were 45.5 " for standard gating and 43.0" for alternative gating. The molds were prepared using silica sand having an AFS grain size of 55 bonded with $4.5 \%$ by sand weight dextrin modified (5\%) sodium silicate (50\% aq.) binder. The heats F5083 and F5085 were meant to be poured with submerged ladle nozzle extension. However, the shrouds started to split longitudinally during pour A and were fully open during pour B. Since use of a shroud is an optional operation, these castings were effectively poured without a nozzle extension. After removing the gates and risers and the castings get cleaned, the experimental conditions and results of cope surface evaluation were given in the following table. 
Evaluation of cope side defects in steel wedge-block castings

\begin{tabular}{|c|c|c|l|}
\hline $\begin{array}{c}\text { Heat No. / } \\
\text { Block ID }\end{array}$ & $\begin{array}{c}\text { Tap temp. / } \\
\text { Pour temp. }\left({ }^{\circ} \mathrm{C}\right)\end{array}$ & $\begin{array}{c}\text { Dirt } \\
\text { Count }\end{array}$ & \multicolumn{1}{|c|}{ Comments } \\
\hline F5071 & 1646 & & Ladle nozzle only. Pour via pouring cup (A) and pouring basin (B). \\
\hline A & 1620 & 24 & Large cope defect at the thin-end. \\
\hline B & 1593 & 5 & Clean except where location for breather holes show in relief. \\
\hline & 1637 & & $\begin{array}{l}\text { Ladle nozzle with extension. Pour via pouring cup (A) and pouring } \\
\text { basin (B). Nozzle extension split open longitudinally to four parts } \\
\text { during Pour A (Fig. ). }\end{array}$ \\
\hline A & 1591 & 8 & Clean \\
\hline B & 1577 & 16 & Small roughness and ripples \\
\hline & 1645 & & $\begin{array}{l}\text { Ladle nozzle with extension. Pour via pouring cup (A) and pouring } \\
\text { basin (B). Nozzle extension split open longitudinally to four parts } \\
\text { during Pour A. Pour B was interrupted before the riser started to fill. }\end{array}$ \\
\hline A & 1603 & 8 & Defects towards thin end and center. \\
\hline B & 1586 & 24 & Very rough, ripples and folds. \\
\hline F5089 & 1642 & & Ladle nozzle only. Pour via pouring cup (A) and pouring basin (B). \\
\hline A & 1603 & 9 & Mostly clean. Open micropores, small ripples. \\
\hline B & 1583 & 20 & Medium rough and ripples. \\
\hline & & &
\end{tabular}

\subsection{Existing possible causes of defect in ABMI}

The castings examined in this experiment include trash plates, billets for cane knife, gear blanks. The external surfaces of all of these castings were examined to identify the type of cavities occurred including the internal sections of many of the items either by cutting through the sections or machining the surfaces. In of Figure 1 (a) shows, the external surface of a trash plate in contact with the cope part of the mold and fig 1(b) illustrates an view of billets for cane knife, fig 1 (c) shows the gear blanks. The internal section of a trash plate as it is hardly scrapped and its large size demanded use of several cutting disks and operator's time.

One of the primary objectives of this study is to obtain the remedies for the existing cavitation problems in steel castings from and within the ongoing traditions and procedures of the production systems that are practically applied in ABMI.

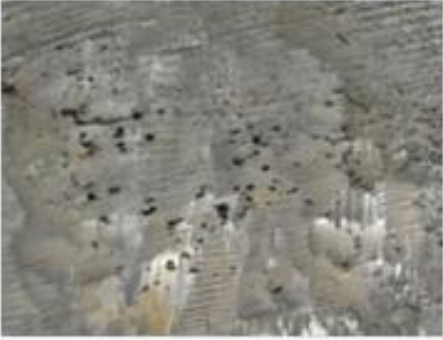

a. trash plate

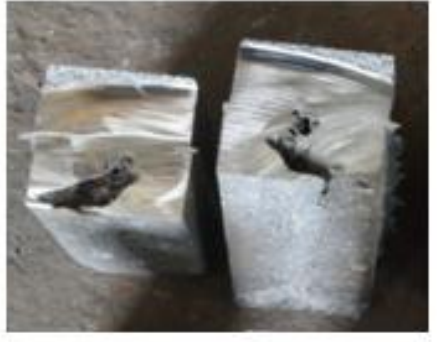

b cane knife billet

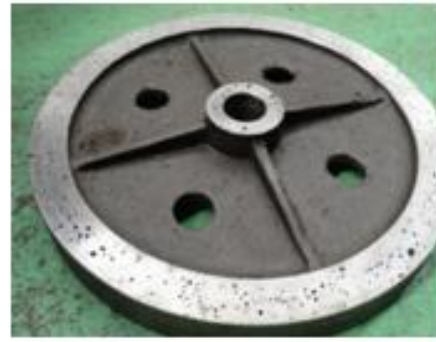

c. gear blank

Figure.1. Surface defect

To this effect a number of activities which may have got some influence to the point of interest of this project were studied in a fairly detailed manner to get some picture of the overall operation of the foundry section. These include:

- use of proper riser, runner and gates in manual mold section

- $\quad$ nature and application of mold paint

- quality of scraps and furnace charges

- control of core and mold moisture

- control of pouring temperature

- control of melt holding and handling time

- use of de-oxidizer material

- control of pouring speed and time

- type of resin material and ratio between sand and binder

- mold permeability and venting procedures

- loss on ignition (LOI) values

- $\quad$ sand moisture content

- grain fineness (GFN) values 
Table 1. Taguchi's array selector table

\begin{tabular}{|c|c|c|c|c|c|c|c|c|c|c|c|c|c|c|c|c|c|c|c|c|c|c|c|c|c|c|c|c|c|c|c|}
\hline & \multicolumn{31}{|c|}{ Number of Parameters (P) } \\
\hline & 2 & 3 & 4 & 5 & 6 & 7 & 8 & 9 & 10 & 11 & 12 & 13 & 14 & 15 & 16 & 17 & 18 & 19 & 20 & 2 & 2 & & 13 & 24 & 25 & 26 & 27 & 28 & 29 & 30 & 31 \\
\hline$\left.\frac{y}{0}\right|^{2}$ & 14 & 14 & 18 & 18 & 18 & 18 & L12 & L12 & $L 12$ & L12 & $L 16$ & $L 16$ & $\angle 16$ & L16 & 132 & 132 & 132 & 132 & 13 & L' & L & & 32 & 132 & L32 & 132 & 132 & 432 & L.32 & L32 & 132 \\
\hline $\left.\begin{array}{c}0 \\
5\end{array}\right]$ & 19 & 19 & 19 & L18 & L18 & L18 & L18 & L27 & L.27 & $\llcorner 27$ & L27 & 127 & 136 & 136 & 136 & L36 & L36 & L38 & L3 & L' & L & & 36 & & & & & & & & \\
\hline 4 & L'46 & L'18 & L'16 & L'18 & L'32 & L'32 & L'32 & L.32 & L'32 & & & & & & & & & & & & & & & & & & & & & & \\
\hline z & 125 & $\angle 25$ & 125 & L25 & 125 & 150 & 150 & 150 & $\angle 50$ & L5O & L.50 & & & & & & & & & & & & & & & & & & & & \\
\hline
\end{tabular}

Consider for instance, in this study,

- $\quad$ six parameters are identified as the most important causes for porosity

- three different levels are set for each parameter.

[6]Then, the name of the appropriate array can be found from the array selector table by looking at the column and row corresponding to the number of parameters and number of levels respectively. Thus, for 6 parameters and 3 levels the appropriate array would be an $\mathrm{L}_{18}$ array. Since the subscript represents the number of experiments, it is required to conduct 18 individual experiments in this study. Note that the numbers 1,2 and 3 in the body of the $\mathrm{L}_{18}$ array below, will be replaced by the values of the levels assigned for each parameter denoted by P1, P2, etc.

\subsection{Sand Moisture content}

Moisture can enter the mold cavity in a number of ways. Those related to the mold paint and moisture absorbed from the atmosphere by the mold after it is prepared is discussed above. [7] Moisture may appear also in sand which is going to be used in mold preparation. To determine the intensity of moisture contributed by the sand to the overall moisture content of the mold in ABMI, the following test has been made. In this test, both new sand used for making cores and reclaimed sand used for making molds as obtained from the sand mixers are considered.

Table 2. Moisture tests for new and reclaimed sands

\begin{tabular}{||c|c||c|c||}
\hline \multicolumn{2}{||c||}{ New Silica Sand } & \multicolumn{2}{c||}{ Reclaimed Sand } \\
\hline \hline Test & $\begin{array}{c}\text { Moisture Content } \\
{[\%]}\end{array}$ & Test & $\begin{array}{c}\text { Moisture Content } \\
{[\%]}\end{array}$ \\
\hline 1 & 0.0 & 1 & 0.4 \\
\hline 2 & 0.4 & 2 & 0.2 \\
\hline 3 & 0.0 & 3 & 0.4 \\
\hline 4 & 0.2 & 4 & 0.4 \\
\hline 5 & 0.2 & 5 & 0.4 \\
\hline 6 & 0.0 & 6 & 0.0 \\
\hline
\end{tabular}

The test results in the above table show that the moisture to be added in the mold cavity from the sand is very little as it is kept below the maximum recommended $-0.5 \%$.

\subsection{Grain Fineness (GFN) values}

Grain fineness has also something to do with permeability of a mold. [8] Molds made of very fine grained sands will be very packed and have little space between the sand grains that wouldn't allow entrapped air and gases to escape - leading to porosity defects. Those made of very coarse grained sands will be unnecessarily open to cause other casting defects. Therefore, the GFN values for molding sands shall remain within a certain range to obtain sound castings. The GFN values as per ABMI's practices are made to stay within $40-60$. The lower (coarser) ranges are used for ferrous and the upper (finer) ranges are used for non ferrous materials. Gases need to be driven out quickly from molds which are made for pouring steel materials and so such molds should be made from coarser sands. The GFN of reclaimed sand is measured and tabulated as follows: 
Table 3. Grain fineness number (GFN) for reclaimed sand

\begin{tabular}{||c|c|c|c|c|c|c||}
\hline $\begin{array}{c}\text { Sieve } \\
\text { Number }\end{array}$ & $\begin{array}{c}\text { Gross wt. [g] } \\
\text { (sieve+ sand) }\end{array}$ & $\begin{array}{c}\text { Net wt. [g] } \\
\text { (sieve) }\end{array}$ & Sandwt. [g] & $\%$ & Coefficient & Product \\
\hline 1.680 & 425.16 & 425.12 & 0.04 & 0.04 & 5.5 & 0.22 \\
\hline 1.190 & 402.49 & 402.47 & 0.02 & 0.02 & 7.5 & 0.15 \\
\hline 0.841 & 364.97 & 364.96 & 0.01 & 0.01 & 10 & 0.10 \\
\hline 0.595 & 376.01 & 374.69 & 1.32 & 1.32 & 20 & 26.4 \\
\hline 0.420 & 351.16 & 341.39 & 9.77 & 9.77 & 30 & 293.1 \\
\hline 0.297 & 344.60 & 317.32 & 27.28 & 27.28 & 40 & 1091.2 \\
\hline 0.210 & 353.42 & 322.39 & 31.03 & 31.03 & 50 & 1551.5 \\
\hline 0.149 & 333.67 & 309.28 & 24.39 & 24.39 & 70 & 1707.3 \\
\hline 0.105 & 303.60 & 298.08 & 5.52 & 5.52 & 100 & 552 \\
\hline 0.075 & 297.87 & 297.43 & 0.44 & 0.44 & 140 & 61.6 \\
\hline 0.053 & 307.36 & 307.27 & 0.09 & 0.09 & 200 & 18 \\
\hline Pan & 394.89 & 394.80 & 0.09 & 0.09 & 270 & 24.3 \\
\hline & & Total & $100 *$ & & & 5325.87 \\
\hline
\end{tabular}

* 100 grams of sand is taken for the test.

$$
\begin{aligned}
\text { GFN } & =\frac{\Sigma \text { Product }}{\text { Initial sand weight }} \\
& =\frac{5325.87}{100}=53.26
\end{aligned}
$$

The above result depicts the GFN values a little above the average towards the finer range therefore, requiring some correction by combining with coarser new silica sand.

\subsection{Parameter Selection using Taguchi's Design of Experiments}

This method involves reducing the variation in a process through robust design of experiments. The overall objective of this method in this thesis project is to identify the optimum combination of process parameters that minimize the formation of gas cavities in steel castings made of $46 \mathrm{MnSi} 4$ steel. This experimental design involves using orthogonal arrays to organize the parameters affecting the casting process and the levels at which they should be varying. Instead of having to test all possible combinations, the Taguchi method tests pairs of combinations to allow collection of the necessary data to determine which factors are most affecting the casting quality with a minimum amount of experimentation, thus saving time and resources.

In order to determine the parameters that affect the formation of porosity and shrinkage defects in $46 \mathrm{MnSi} 4$ steel castings, a number of discussions were made with concerned technicians in the manual as well as mechanized molding sections, melting section and methods design section. The probable parameters/causes suggested by the respective sections in ABMI are listed in the following table:

Table. 4. Parameters causing gas and shrinkage cavitation's as proposed by technicians in ABMI

\begin{tabular}{||l|l|l||}
\hline Methods Design section & \multicolumn{1}{|c|}{ Molding section } & \multicolumn{1}{|c|}{ Melting section } \\
\hline \hline Wrong position of riser & Poor sand quality & Pouring temperature \\
\hline Wrong size of riser & Mold moisture & Pouring time \\
\hline & Mold paint & Scrap quality \\
\hline & Poor venting & De-oxidant amount \\
\hline & High LOI & Holding time \\
\hline & High clay content & \\
\hline
\end{tabular}

In fact these are not the only parameters causing porosity and shrinkage defects in steel castings. [9,10] Permeability of molds, binder type and quantity, grain fineness values, sharp corners in the gating systems, lack of streamlined pouring basin and other relevant scenarios also play huge roles in causing such defects. In the actual experiment however, most of these causes will be taken care of thoroughly in mold design and preparation beforehand. Since it won't be practical to examine all the potential causes in the experiment, those which have greater influence on the subject defect and also relatively simpler to control will be treated as far as possible. Thus the following parameters were selected for use in the experimental design: 
1. Mold moisture content

2. Sand - binder ratio

3. Mold permeability

4. Pouring temperature

5. De-oxidant amount used

\begin{tabular}{|c|c|c|c|c|}
\hline & \multicolumn{4}{|c|}{ Parameters } \\
\hline & $\begin{array}{l}\text { Sand - binder } \\
\text { ratio }(\mathrm{kg})\end{array}$ & $\begin{array}{l}\text { Mold } \\
\text { permeability }\end{array}$ & $\begin{array}{l}\text { Pouring } \\
\text { Temp. }\left({ }^{\circ} \mathrm{C}\right)\end{array}$ & $\begin{array}{l}\text { De-oxidant } \\
\text { amount }(\%)\end{array}$ \\
\hline \multirow{3}{*}{ Levels } & $\begin{array}{l}\text { Minimum } \\
(100: 0.9)\end{array}$ & $\begin{array}{l}\text { Low } \\
(150-200)\end{array}$ & $\begin{array}{l}\text { Cold } \\
(1460-1490)\end{array}$ & $\begin{array}{l}\text { Few } \\
(0.1)\end{array}$ \\
\hline & $\begin{array}{l}\text { Average } \\
(100: 1.0)\end{array}$ & $\begin{array}{l}\text { Medium } \\
(201-250)\end{array}$ & $\begin{array}{l}\text { Mild } \\
(1491-1520)\end{array}$ & $\begin{array}{l}\text { Intermediate } \\
(0.2)\end{array}$ \\
\hline & $\begin{array}{l}\text { Maximum } \\
(100: 1.2)\end{array}$ & $\begin{array}{l}\text { High } \\
(251-300)\end{array}$ & $\begin{array}{l}\text { Hot } \\
(1521-1550)\end{array}$ & $\begin{array}{l}\text { Many } \\
(0.3)\end{array}$ \\
\hline
\end{tabular}

From the actual data taken from ABMI's practices and preliminary experimental results shown in the previous section, the states or levels to which the above parameters will be varying are taken into consideration and shown in the table 5.

\section{RESULT AND DISCUSSION}

In this experiment the sand binder ratio, mold permeability, pouring temperature and de oxidant amount of different combinations are taken for conducting the experiment at different time of intervals. The results obtained out of this experiment are recorded and presented in table 6

Table 6. The achievement of casting operations

\begin{tabular}{|l|l|l|l|l|}
\hline $\begin{array}{l}\text { Experiment } \\
\text { No. }\end{array}$ & $\begin{array}{l}\text { Sand-binder } \\
\text { ratio (kg) }\end{array}$ & $\begin{array}{l}\text { Mold } \\
\text { permeability }\end{array}$ & $\begin{array}{l}\text { Pouring } \\
\text { Temp. }\left({ }^{\circ} \mathbf{C}\right)\end{array}$ & $\begin{array}{l}\text { De-0xidant } \\
\text { amount (\%) }\end{array}$ \\
\hline 1 & $100: 0.9$ & $150-200$ & $1460-1490$ & 0.1 \\
\hline 2 & $100: 0.9$ & $200-250$ & $1491-1520$ & 0.2 \\
\hline 3 & $100: 0.9$ & $250-300$ & $1521-1550$ & 0.3 \\
\hline 4 & $100: 1$ & $150-200$ & $1491-1520$ & 0.3 \\
\hline 5 & $100: 1$ & $200-250$ & $1521-1550$ & 0.1 \\
\hline 6 & $100: 1$ & $250-300$ & $1460-1490$ & 0.2 \\
\hline 7 & $100: 1.2$ & $150-200$ & $1521-1550$ & 0.2 \\
\hline 8 & $100: 1.2$ & $200-250$ & $1460-1490$ & 0.3 \\
\hline 9 & $100: 1.2$ & $250-300$ & $1491-1520$ & 0.1 \\
\hline
\end{tabular}

The nine experimental observations are shown in table 7.

Table. 7. Experimental observations

\begin{tabular}{|l|l|l|l|l|l|}
\hline $\begin{array}{l}\text { Experiment } \\
\text { No. }\end{array}$ & $\begin{array}{l}\text { Sand } \\
\text { binder } \\
\text { ratio (kg) }\end{array}$ & $\begin{array}{l}\text { Mold } \\
\text { permeability }\end{array}$ & $\begin{array}{l}\text { Pouring } \\
\text { Temp. } \\
\left({ }^{\circ} \mathrm{C}\right)\end{array}$ & $\begin{array}{l}\text { De-oxidant } \\
\text { amount (\%) }\end{array}$ & $\begin{array}{l}\text { Defect } \\
\text { intensity/porosity/ }\end{array}$ \\
\hline 1 & Minimum & Low & Cold & Few & Severe \\
\hline 2 & Minimum & Medium & Mild & Intermediate & Moderate \\
\hline 3 & Minimum & High & Hot & Many & Moderate \\
\hline 4 & Average & Low & Mild & Many & Severe \\
\hline 5 & Average & Medium & Hot & Few & Traces \\
\hline 6 & Average & High & Cold & Intermediate & Nil to Trace \\
\hline 8 & Maximum & Low & Hot & Intermediate & Severe \\
\hline 9 & Maximum & Medium & Cold & Many & Severe \\
\hline
\end{tabular}


In fig.2. shows the result of different experiments. It is found that the experimental no 6 shows the encourage able results for taking the necessary action for changing the process parameters. But with different combinations and adding some more parameters may be results can give scope for further minimize the casting defects.
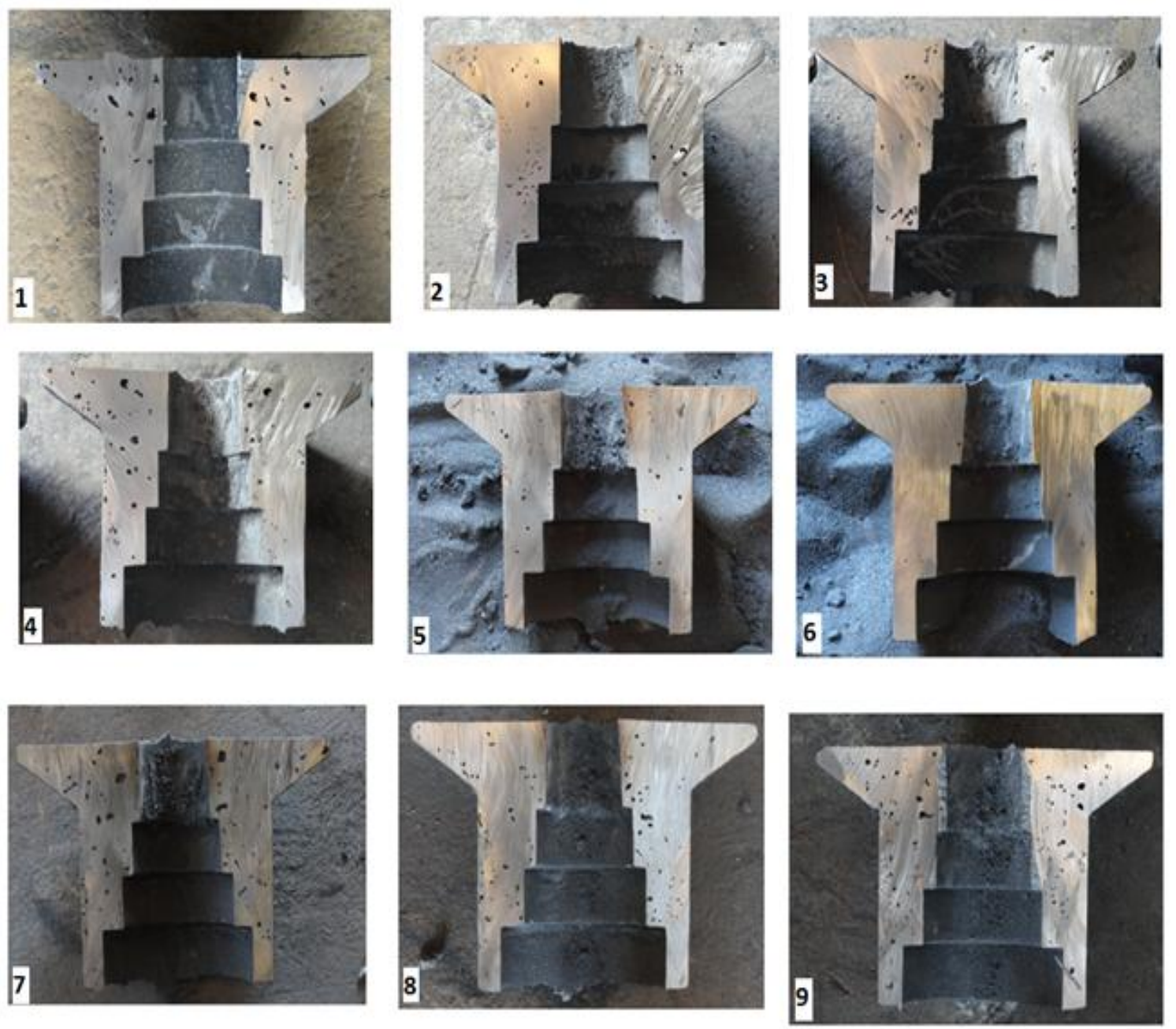

Fig. 2. A steel casting section resulted from 9 experiment

\section{CONCLUSION}

There are 9 experiments conducted using Taguchi's DOE by changing the selected variables and different results, from very bad to good, were shown up. The shrinkage defect was precluded starting the first experiment since it can usually be corrected by proper design of the gating systems. In fact, much more experiments were needed to determine the clear causes of gas defects as such causes are so many in number. Any ways, if the matrix of the variables that produce good result can be applied by ABMI, there will obviously be a substantial saving in the cost of production. Gas defects have a number of different causes which are sometimes unique to a certain environment and working conditions. Increasing the number of parameters and variables would give more accurate results and enables to know the effect of any individual variable on the defect scenario but, it costs is high. From among a lot of known porosity causing parameters, this project considers only 4 of them; namely, sand-binder ratio, mold moisture, pouring temperature, and amount of deoxidant material added to the melt. Moreover, keeping the parameters the same the variables can still be made to assume other values so that different out puts can be expected. In this project however, limited variables and relatively larger temperature ranges are taken.

Finally the conducted experiments, it is clearly evident that the trail of experiment 6 is the better combination of the parameters like sand binder ratio, mold permeability, pouring temperature and de oxidant amount are the leading parameters for optimizing the process in order to minimize the casting defects.

The future scope of this experiment can further guide in selecting the various combinations for the process with mode trails can help in minimizing the defects of castings. 


\section{REFERENCE}

[1]. Peter Beeley, "Foundry Technology", Butter Worth Heinemann, $2^{\text {nd }}$ ed., 2001

[2]. R. Monroe, "Porosity in Castings", American Foundry Society, Paper 05-245(04), 2005

[3]. Dr. R.L. Naro, "Porosity Defects in Iron Castings from Mould-Metal Interface Reactions" Paper (99-206) March 15, 1999 http://www.cn-steelpipe.net/stainless-steel-news/IC44D.html "Casting Defects in Steels", Update 2008-7-21

[4]. S. Kuyucak, "Sponsored Research: Clean Steel Casting production - Evaluation of Laboratory Castings", American Foundry Society, 2007

[5]. J.S. Campbell, "Principles of Manufacturing Materials and Processes", Tata McGraw Hill Book Co. Inc., New Delhi,1992D.C. Ekey \& W.P. Winter, "Introduction to Foundry Technology", McGraw Hill Book Co. Inc., New York, 1958

[6]. John Campbell, "Castings”, Elsevier Science Ltd., Great Britain, 1991

[7]. N.D. Tutov, Yu.A. Stepanov, "Foundry Practice", Mir Publishers, Moscow, 1981

[8]. P. Bidulya, "Steel Foundry Practice", Mir Publishers, Moscow, 1968s"

[9]. Dr. A.K.M.B. Rashid, "Design of Gating and Feeding Systems", Materials \& Metallurgical Engineering 346 - Foundry Engineering Sessional

[10]. S. Guleyupoglu, "Casting Process Design Guidelines", Concurrent Technologies Corporation, Pennsylvania

\section{Authors Bibliography:}

Achamyeleh Aemro Kassie received his B.Sc. Degree in Mechanical Engineering from Addis Ababa University, Ethiopia. He received M.Tech. Degree from NIT, Warangal, India. Currently working as Lecture in the School of Mechanical and Industrial Engineering, Institute of Technology, Bahir Dar University, Bahir Dar, Ethiopia.

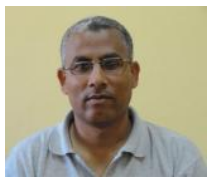

Samuel B. Assfaw received M.SC. Degree from Bahirdar University, Bahirdar, Ethiopia. Currently working as Lecture in the School of Mechanical and Industrial Engineering, Institute of Technology, Bahir Dar University, Bahir Dar, Ethiopia. 